\title{
ALTERED PROINFLAMMATORY CYTOKINES AND M1 POLARIZATION INDUCED BY PM2.5 IN ALVEOLAR MACROPHAGES
}

\author{
MOON, D. ${ }^{1 \#-P A R K}$, S. J. ${ }^{2 \#}-$ KIM, S. ${ }^{3}-$ KIM, J. ${ }^{3}-$ KIM, M. ${ }^{3}-$ KIM, K. ${ }^{3}-$ KIM, Y. S. $.^{4 *}-$ KIM, J. ${ }^{1,5^{*}}$ \\ ${ }^{1}$ Department of Biomedicine and Drug Development, Jeju National University \\ Jeju 63243, Republic of Korea \\ ${ }^{2}$ Department of Biology, Jeju National University \\ Jeju 63243, Republic of Korea
}

${ }^{3}$ Air Environmental Division, Jeju Special Self-Governing Province Research Institute of Health \& Environment, Jeju 63243, Republic of Korea

${ }^{4}$ Department of Radiation Oncology, Jeju National University Hospital and Jeju National University School of Medicine, Jeju 63241, Republic of Korea

${ }^{5}$ Department of Anatomy, Jeju National University School of Medicine

Jeju, Republic of Korea

*Corresponding authors

e-mail: jinu.kim@jejunu.ac.kr (J.Kim),yskim@jejunuh.co.kr (Y.S.Kim)

phone: +82-64-754-8181; fax: +82-64-702-2687

${ }^{\#}$ These authors contributed equally to this work.

(Received 25 $5^{\text {th }}$ Jul 2018; accepted $15^{\text {th }}$ Oct 2018)

\begin{abstract}
Exposure to atmospheric particulate matter with aerodynamic diameter less than $2.5 \mu \mathrm{m}$ (PM2.5) is epidemiologically implicated in pulmonary mortality and diseases. While it is known that PM2.5-exposed macrophages produce and secrete inflammatory cytokines, it is not clear how PM2.5 contributes to the upregulation of proinflammatory cytokines in alveolar macrophages. Therefore, the present study aims to investigate the molecular mechanism of macrophage inflammatory responses to PM2.5. In a MH-S mouse alveolar macrophage cell line, exposure to PM2.5 significantly increased the

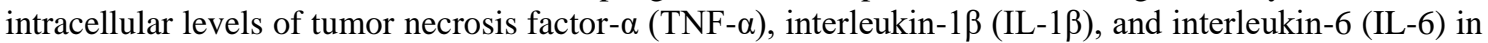
dose- and time-dependent manners, while it did not alter those of transforming growth factor- $\beta 1$ (TGF$\beta 1$ ) and interleukin-10 (IL-10). PM2.5 also increased the expressional level of CD80 mRNA, but did not alter that of CD163 mRNA in alveolar macrophages, suggesting PM2.5-induced M1 phenotypic polarization. Treatment with nuclear factor- $\mathrm{kB}$ (NF- $\mathrm{\kappa B})$ inhibitors immediately after PM2.5 administration reduced the production of TNF- $\alpha$, IL-1 $\beta$, and IL- 6 upregulated by PM 2.5 , and attenuated the CD80 mRNA expression induced by the PM2.5 exposure. In conclusion, these data suggest that PM2.5 exposure in alveolar macrophages induces the upregulation of proinflammatory cytokines as well as polarization to the $\mathrm{M} 1$ phenotype through the $\mathrm{NF}-\mathrm{KB}$ activation.
\end{abstract}

Keywords: air pollution, Jeju Island, lung, $C D 80, N F-\kappa B$

\section{Introduction}

Global air pollution has a major impact on the health of humans and organisms' lives as well as the natural environment (Kampa and Castanas, 2008). Among the primary air pollutants including particulate matter (PM), carbon monoxide, lead, nitrogen dioxide, ozone, and sulfur dioxide, PM is a complex mixture of airborne solid particles and liquid droplets, consisting of acids, organic chemicals, metals, and dust particles 
(Anderson et al., 2012). In several epidemiological studies, the elevated level of PM is estimated to be associated with increased mortality and hospitalization (Kim et al., 2015b). Especially, because PM2.5 with an aerodynamic diameter of less than $2.5 \mu \mathrm{m}$ contains various toxic substances and penetrates deeply into the lungs, considerable studies have shown that PM2.5 triggers severe respiratory diseases including bronchitis, asthma, chronic obstructive pulmonary disease, and lung cancer as well as mild problems including chest pain, coughing, and wheezing (Abbey et al., 1995; Ko et al., 2007; Tecer et al., 2008; Vinikoor-Imler et al., 2011). Experimental laboratory evidence suggests that exposure to PM2.5 induces the production of proinflammatory cytokines, the generation of reactive oxygen species, and alteration in macrophage polarization during lung injury (Deng et al., 2013; Riva et al., 2011; Zhao et al., 2016). Nevertheless, studies on the relationship between PM2.5 and the inflammatory response in alveolar macrophages are still limited.

The alveolar macrophage is a tissue-resident phagocyte just as Kupffer cells in the liver, Langerhans cells in the skin, osteoclasts in bone, and microglial cells in the central nervous system. The alveolar macrophage is the only macrophage living in aerobic conditions; and constitutes the first line of phagocytic defense against inhaled particles and microbial agents in the alveolar space (Hocking and Golde, 1979). In particular, these cells play a critical role in lung defense systems through their ability to scavenge the inhaled particles and microbial agents that infiltrate the gas-exchanging airway, recruit polymorphonuclear leukocytes from the pulmonary vasculature into the alveolar spaces, and regulate the immune response. Although the crucial proinflammatory mediators produced by alveolar macrophages, such as tumor necrosis factor- $\alpha$ (TNF- $\alpha)$, interleukin-1 $\beta$ (IL-1 $\beta$ ), and interleukin-6 (IL-6), are beneficial to lung defense in vivo, the excessive production of these cytokines is involved in the pathogenesis of inflammatory and allergic lung diseases, which can result in lung dysfuction. Previous studies have often shown the induction of proinflammatory cytokines by exposure to PM2.5 in RAW264.7 macrophages derived from mouse peripheral blood (Jalava et al., 2007) and THP-1 monocytes derived from human peripheral blood (Corsini et al., 2013; Zhang et al., 2018), but have not shown that in alveolar macrophages. Some investigators have used primary cultures of alveolar macrophages derived from lungs of humans and rats for studies on the proinflammatory activity of PM2.5 (Hetland et al., 2005; Soukup and Becker, 2001b); however, the application of primary alveolar macrophage cultures in experimental studies is difficult due to the instability of their phenotype and function ex vivo (Wang et al., 2013). Furthermore, polarized macrophages including alveolar macrophage can be commonly classified into two main phenotypes (Martinez et al., 2008). Between both types, M1 macrophages polarized by Th1-type cytokines and pathogens promote inflammation through upregulating proinflammatory cytokines, and increase the production of reactive oxygen species and nitrogen intermediates. In contrast, M2 macrophages are closely related to the Th2 type and immunomodulatory cytokines, which primarily suppress inflammation (Gordon, 2007). However, the precise mechanisms of the proinflammatory cytokine induction and the polarization in alveolar macrophages by PM2.5 are still unclear.

Nuclear factor- $\kappa \mathrm{B}(\mathrm{NF}-\kappa \mathrm{B})$ transcription factors are known to play an important role in immune and inflammatory responses (Lenardo and Baltimore, 1989). The activation of the NF- $\kappa \mathrm{B}$ signaling pathway requires the signal transduction of external stimuli including bacterial lipopolysaccharide, oxidants, viruses, and cytokines. Especially, the level of proinflammatory cytokines including TNF- $\alpha$, IL-1 $\beta$, and IL- 6 is regulated by 
$\mathrm{NF}-\kappa \mathrm{B}$, while these cytokines stimulate the activation of NF- $\mathrm{BB}$ and induce a cascade of proinflammation. Although PM2.5 has been shown to activate NF- $\kappa \mathrm{B}$ in alveolar epithelial cells and peripheral macrophages (Dagher et al., 2007; He et al., 2017), the involvement in NF- $\mathrm{kB}$ signaling induction by PM2.5 in alveolar macrophages remains unknown. Therefore, we attempted to determine whether the PM2.5-induced upregulation of cytokines is dependent on the NF- $\kappa B$ signaling pathway in the HM-S alveolar macrophages derived from mouse lungs. In addition, to clarify the mechanism of PM2.5-induced lung inflammation, we evaluated whether PM2.5 acts directly on alveolar macrophage polarizations under the cell culture condition without any inducing systems for macrophage polarization.

\section{Materials and methods}

\section{PM2.5 preparation and chemical analysis}

PM2.5 was collected by the Jeju Special Self-Governing Province Research Institute of Health \& Environment during September 2017 from a measuring station at latitude $33^{\circ} 29^{\prime} 19.2^{\prime \prime}$ north and longitude $126^{\circ} 30^{\prime} 00.5^{\prime \prime}$ east in Yeondong, which is located in the northern area of Jeju Island, Republic of Korea. The samples were performed on quartz filters (Millipore, Bedford, MA, USA) for biological analysis and polytetrafluoroethylene (PTFE) fiber membrane filters (Millipore) for chemical analysis using a PM2.5 sequential sampler (PMS-103, APM, Bucheon, Korea). To carry out biological studies using the PM2.5, the quartz filters were detached from plastic containers with care to avoid material loss or contamination, weighted using a microbalance (XP6, Mettler Toledo, Columbus, OH, USA) to calculate the weight of PM2.5, immersed in Roswell Park Memorial Institute (RPMI) 1640 culture medium (Welgene, Daegu, Korea) at a final concentration of $100 \mu \mathrm{g} / \mathrm{ml}$, and sonicated for 60 min at room temperature in a sonicating water bath (Branson Ultrasonics, Danbury, CT, USA). The PM2.5 extract in RPMI 1640 was stored at $-80^{\circ} \mathrm{C}$ and resuspended just prior to use. To analyze the water soluble components in the PM2.5, the halves of PTFE filters were exposed to constant temperature $\left(20^{\circ} \mathrm{C}\right)$ and humidity $(45 \%)$ for $24 \mathrm{~h}$, weighted using a microbalance (XP6, Mettler Toledo) to calculate the weight of PM2.5, soaked in $100 \mu \mathrm{l}$ ethanol, immersed in $10 \mathrm{ml}$ distilled water, sonicated for $60 \mathrm{~min}$, and filtrated using a $0.45 \mu \mathrm{m}$ polyvinylidene fluoride (PVDF) syringe filter. The PM2.5 extract in $1 \%$ ethanol was used to measure the water soluble components including $\mathrm{Ca}^{2+}, \mathrm{K}^{+}, \mathrm{Mg}^{2+}, \mathrm{Na}^{+}, \mathrm{NH}^{4+}, \mathrm{Cl}^{-}, \mathrm{NO}_{3}{ }^{-}$, and $\mathrm{SO}_{4}{ }^{2-}$ using an ion chromatography (Dionex ICS-2000, Dionex, Sunyvale, CA, USA). To analyze the elements in the PM2.5, the other halves of PTFE filters were exposed to constant temperature $\left(20^{\circ} \mathrm{C}\right)$ and humidity (45\%) for $24 \mathrm{~h}$, weighted using a microbalance (XP6, Mettler Toledo) to calculate the weight of PM2.5, digested with $10 \mathrm{ml}$ solvent $\left(5.55 \% \mathrm{HNO}_{3}+16.75 \% \mathrm{HCl}\right)$ in a microwave digestion system (ETHOS One, Milestone, Sorisole, Italy) at $200^{\circ} \mathrm{C}$ for 30 min, supplemented with $10 \mathrm{ml}$ distilled water and filtrated using a $0.45 \mu \mathrm{m}$ PVDF syringe filter. The PM2.5 extract in the solvent was used to measure the elements including $\mathrm{Al}, \mathrm{As}, \mathrm{Ba}, \mathrm{Ca}, \mathrm{Cd}, \mathrm{Co}, \mathrm{Cr}, \mathrm{Cu}, \mathrm{Fe}, \mathrm{K}, \mathrm{Mg}, \mathrm{Mn}, \mathrm{Mo}, \mathrm{Na}, \mathrm{Ni}, \mathrm{Pb}, \mathrm{Se}, \mathrm{Sr}, \mathrm{Ti}, \mathrm{U}$, $\mathrm{V}$, and $\mathrm{Zn}$ using an inductively coupled plasma mass spectrometry (ICP-MS; Agilent 7800, Agilent Technologies, Tokyo, Japan). Table 1 shows the results of chemical analysis. 
Table 1. Concentrations ( $\mu \mathrm{g} / \mathrm{mg}$ PM2.5/day) of elements and water soluble components in PM2.5

\begin{tabular}{|c|c|c|c|}
\hline \multicolumn{2}{|c|}{ Element (mean \pm s.d.) } & \multicolumn{2}{|c|}{ Water soluble component (mean \pm s.d.) } \\
\hline $\mathrm{Al}$ & $4.58 \pm 1.14$ & $\mathrm{Ca}^{2+}$ & $2.86 \pm 0.92$ \\
\hline As & $0.14 \pm 0.07$ & $\mathrm{~K}^{+}$ & $7.47 \pm 3.72$ \\
\hline $\mathrm{Ba}$ & $0.29 \pm 0.04$ & $\mathrm{Mg}^{2+}$ & $1.66 \pm 0.60$ \\
\hline $\mathrm{Ca}$ & $3.77 \pm 0.34$ & $\mathrm{Na}^{+}$ & $7.09 \pm 3.56$ \\
\hline $\mathrm{Cd}$ & $0.03 \pm 0.02$ & $\mathrm{NH}_{4}^{+}$ & $139.25 \pm 75.61$ \\
\hline Co & $0.01 \pm 0.01$ & $\mathrm{Cl}^{-}$ & $1.04 \pm 0.69$ \\
\hline $\mathrm{Cr}$ & $0.31 \pm 0.27$ & $\mathrm{NO}_{3}^{-}$ & $2.94 \pm 1.97$ \\
\hline $\mathrm{Cu}$ & $0.20 \pm 0.07$ & $\mathrm{SO}_{4}^{2-}$ & $430.59 \pm 257.63$ \\
\hline $\mathrm{Fe}$ & $7.53 \pm 3.30$ & & \\
\hline $\mathrm{K}$ & $7.54 \pm 3.80$ & & \\
\hline $\mathrm{Mg}$ & $5.07 \pm 0.89$ & & \\
\hline $\mathrm{Mn}$ & $0.38 \pm 0.16$ & & \\
\hline Mo & $0.04 \pm 0.03$ & & \\
\hline $\mathrm{Na}$ & $27.16 \pm 2.76$ & & \\
\hline $\mathrm{Ni}$ & $0.69 \pm 0.97$ & & \\
\hline $\mathrm{Pb}$ & $0.66 \pm 0.34$ & & \\
\hline $\mathrm{Se}$ & $0.11 \pm 0.08$ & & \\
\hline $\mathrm{Sr}$ & n.d. & & \\
\hline $\mathrm{Ti}$ & $0.41 \pm 0.10$ & & \\
\hline $\mathrm{U}$ & n.d. & & \\
\hline $\mathrm{V}$ & $0.38 \pm 0.18$ & & \\
\hline $\mathrm{Zn}$ & $2.74 \pm 0.75$ & & \\
\hline
\end{tabular}

$\mathrm{Ca}^{2+}$, calcium cation; $\mathrm{K}^{+}$, potassium cation; $\mathrm{Mg}^{2+}$, magnesium cation; $\mathrm{Na}^{+}$, sodium cation; $\mathrm{NH}^{4+}$, ammonium cation; $\mathrm{Cl}^{-}$, chloride ion; $\mathrm{NO}_{3}{ }^{-}$, nitrate ion; $\mathrm{SO}_{4}{ }^{2-}$, sulfate ion; $\mathrm{Al}$, aluminum; As, arsenic; $\mathrm{Ba}$, barium; $\mathrm{Ca}$, calcium; $\mathrm{Cd}$, cadmium; $\mathrm{Co}$, cobalt; $\mathrm{Cr}$, chromium; $\mathrm{Cu}$, copper; $\mathrm{Fe}$, iron; $\mathrm{K}$, potassium; $\mathrm{Mg}$, magnesium; Mn, manganese; Mo,molybdenium; $\mathrm{Na}$, sodium; $\mathrm{Ni}$, nickel; $\mathrm{Pb}$, lead; Se, selenium; $\mathrm{Sr}$,strontium; Ti, titanium; $\mathrm{U}$, uranium; $\mathrm{V}$, vanadium; Zn, zinc; n.d., not detectable

\section{Cell culture and treatment}

The HM-S mouse alveolar macrophage cell line (American Type Culture Collection, Rockville, MD) were cultured in RPMI 1640 supplemented with $10 \%$ fetal bovine serum (FBS; Welgene) at $37^{\circ} \mathrm{C}$ with $5 \% \mathrm{CO}_{2}$ as previously described (Kim, 2016; Park et al., 2015; Song et al., 2016; Yoon and Kim, 2016). The cells were grown until 70\% confluence on $60-\mathrm{mm}$ cell culture dishes. After that, the culture was treated with PM2.5 at a final concentration of $0,1,3,10$, or $30 \mathrm{mg} / \mathrm{ml}$ for $0,1,3,6$, or $24 \mathrm{~h}$. Some cells were treated with either Ro $106-9920$ (1 to $10 \mu \mathrm{M})$, pyrrolidinedithiocarbamate ammonium (PDTC, 10 to $100 \mu \mathrm{M})$, or vehicle $(0.1 \%$ dimethyl sulfoxide, DMSO)

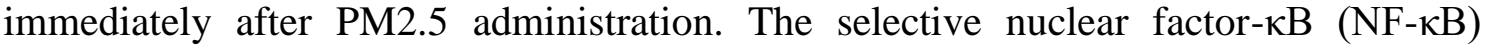
inhibitor Ro 106-9920 and PDTC were purchased from R\&D Systems (Minneapolis, MN, USA).

\section{Enzyme-linked immunosorbent assay (ELISA)}

The levels of TNF- $\alpha$, IL- $1 \beta$, IL-6, transforming growth factor- $\beta 1$ (TGF- $\beta 1$ ) and interleukin-10 (IL-10) production were measured in $10 \mu \mathrm{g}$ protein in $10 \mu \mathrm{l}$ cell lysates using multiplex immunoassay (Millipore) as previously described (Kim, 2017a; Kim et 
al., 2014; Kim et al., 2015a; Yoon and Kim, 2015). The DNA-binding activity of NF$\kappa \mathrm{B}$ p65 was measured in the nuclear extracts of cells using the TransAM NF- $\kappa$ B p65 transcription factor assay kit (Active Motif, Carlsbad, CA, USA). All ELISA experiments were rigorously performed according to respective manufacturer's protocols.

\section{Real-time quantitative RT-PCR}

Total RNA from cells was extracted using TRIzol reagent (ThermoFisher Scientific, Pittsburgh, PA, USA) and cleaned with RNeasy mini kit (Qiagen, Hilden, Germany). After cDNA synthesis using iScript cDNA synthesis kit (Bio-Rad, Hercules, CA, USA), mRNA levels were evaluated using a SYBR Green master mix on an ABI Prism 7500 sequence detection system (Applied Biosystems, Foster City, CA) as previously described (Kim et al., 2012). The following primers were used: mouse cluster of differentiation 80 (CD80; forward: GGCAAGGCAGCAATACCTTA; reverse: CTCTTTGTGCTGCTGATTCG) and mouse cluster of differentiation 163 (CD163; forward: TCCACACGTCCAGAACAGTC; reverse: CCTTGGAAACAGAGACAGGC). Cycle conditions were as follows: after an initial hold of $2 \mathrm{~min}$ at $50^{\circ} \mathrm{C}$ and $10 \mathrm{~min}$ at $95^{\circ} \mathrm{C}$, the samples were cycled 40 times at $95^{\circ} \mathrm{C}$ for $15 \mathrm{sec}$ and $60^{\circ} \mathrm{C}$ for $60 \mathrm{sec}$. Their levels were normalized to the mouse peptidylprolyl isomerase A signal amplified in a separate reaction (forward: TATCTGCACTGCCAAGACTGAATG; reverse: CTTCTTGCTGGTCTTGCCATTCC).

\section{Western blot}

Electrophoresis of $50 \mu \mathrm{g}$ protein in cell lysates on Any kD Mini-PROTEIN TGX gels (Bio-Rad, Hercules, CA, USA) using tris-glycine buffer systems and subsequent blotting onto PVDF membranes were performed as previously described (Kim, 2017b; Lee et al., 2015; Yoon and Kim, 2018a; Yoon and Kim, 2018b). Membranes were

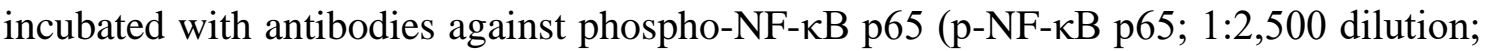
catalog no. 3033, Cell Signaling, Beverly, MA, USA), NF-кB p65 (1:2,500 dilution; catalog no. 8242, Cell Signaling), and $\beta$-actin (1:5,000 dilution; catalog no. A2228; Sigma, St. Louis, MO) overnight at $4{ }^{\circ} \mathrm{C}$, respectively. After washing, peroxidase antirabbit IgG antibodies (1:5,000 dilution; catalog no. WB-1000; Vector Laboratories, Burlingame, CA, USA) against $\mathrm{p}-\mathrm{NF}-\kappa \mathrm{B}$ p65 and NF- $\kappa \mathrm{B}$ p65 antibodies, and peroxidase anti-mouse IgG antibodies (1:5,000 dilution; catalog no. WB-2000; Vector Laboratories) against $\beta$-actin antibody were applied for $1 \mathrm{~h}$ at room temperature. After that, Western Lighting chemiluminescence reagent (NEL101; PerkinElmer, Boston, MA, USA) was used to detect proteins. The anti- $\beta$-actin antibody was used for loading control on stripped membranes. The bands were quantified using AzureSpot analysis software (Azure Biosystems, Dublin, CA, USA).

\section{Statistical analysis}

Analysis of variance was used to compare data among groups using Systat SigmaPlot (Systat Software Inc., San Jose, CA, USA). Differences between two groups were assessed by two-tailed unpaired Student's t-tests. P values $<0.05$ were considered statistically significant. 


\section{Results}

\section{PM2.5 upregulates proinflammatory cytokines, but does not alter anti-inflammatory cytokines in alveolar macrophages}

To determine whether proinflammatory cytokines are upregulated after exposure to PM2.5 in alveolar macrophages, we measured the protein production of TNF- $\alpha$, IL- $1 \beta$, and IL-6 cytokines at $24 \mathrm{~h}$ after PM2.5 administration in MH-S cells. PM2.5 significantly increased the levels of these cytokines in a dose-dependent manner (Fig. 1, a to $c$ ). Especially, the TNF- $\alpha$ and IL-6 productions were more susceptible to a low concentration of PM2.5 $(3 \mu \mathrm{g} / \mathrm{ml})$ than IL-1 $\beta$ production (Fig. 1, a to c). Next, we tested whether PM2.5-treated alveolar macrophages produce anti-inflammatory cytokines including TGF- $\beta 1$ and IL-10. The intracellular levels of those proteins were not significantly altered at $24 \mathrm{~h}$ after PM2.5 administration (Fig. 1, $d$ and e).

a

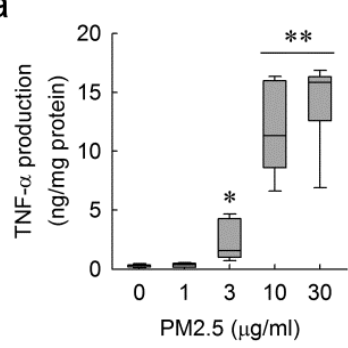

d

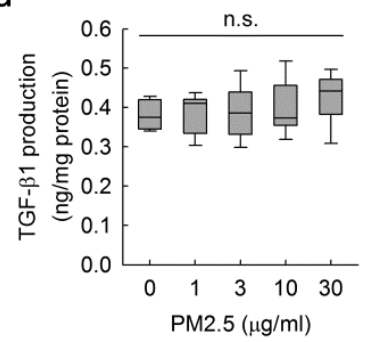

b

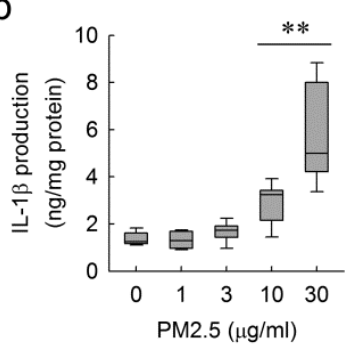

e

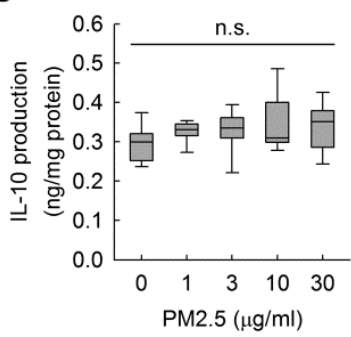

c

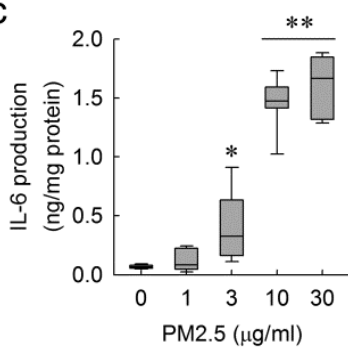

Figure 1. PM2.5 dose-dependently upregulates proinflammationy cytokines in alveolar macrophages. MH-S cells were treated with 0, 1, 3, 10, or $30 \mu \mathrm{g} / \mathrm{ml}$ of PM2.5 for $24 \mathrm{~h}(\mathrm{n}=9$ cultures in each group). Intracellular levels of cytokine TNF- $\alpha, I L-1 \beta, I L-6, T G F-\beta 1$ and $I L-$ 10 were measured using the multiplex immunoassay. In the box plots, whiskers represent the minimum and maximum; boxes represent the interquartile range between the first and third quartiles; and midlines represent the median. ${ }^{*} P<0.01$ and ${ }^{*} P<0.001$ versus $0 \mu \mathrm{g} / \mathrm{ml} ;$ n.s., not significant

In addition, to assess the proinflammatory and anti-inflammatory cytokine productions during early exposure to PM2.5 in alveolar macrophages, the protein levels of TNF- $\alpha$, IL-1 $\beta$, IL-6, TGF- $\beta 1$, and IL-10 were measured at 1,3 , and $6 \mathrm{~h}$ after PM2.5 administration in $\mathrm{MH}-\mathrm{S}$ cells. The levels of proinflammatory cytokines including TNF$\alpha$, IL-1 $\beta$, and IL-6 were markedly enhanced during PM2.5 exposure in a time-dependent manner (Fig. 2, a to c), but the levels of anti-inflammatory cytokines including TGF- $\beta 1$ and IL-10 were not significantly altered (Fig. 2, $d$ and e). Taken together, these data suggest that PM2.5 specifically induces the upregulation of proinflammatory cytokines in alveolar macrophages. 

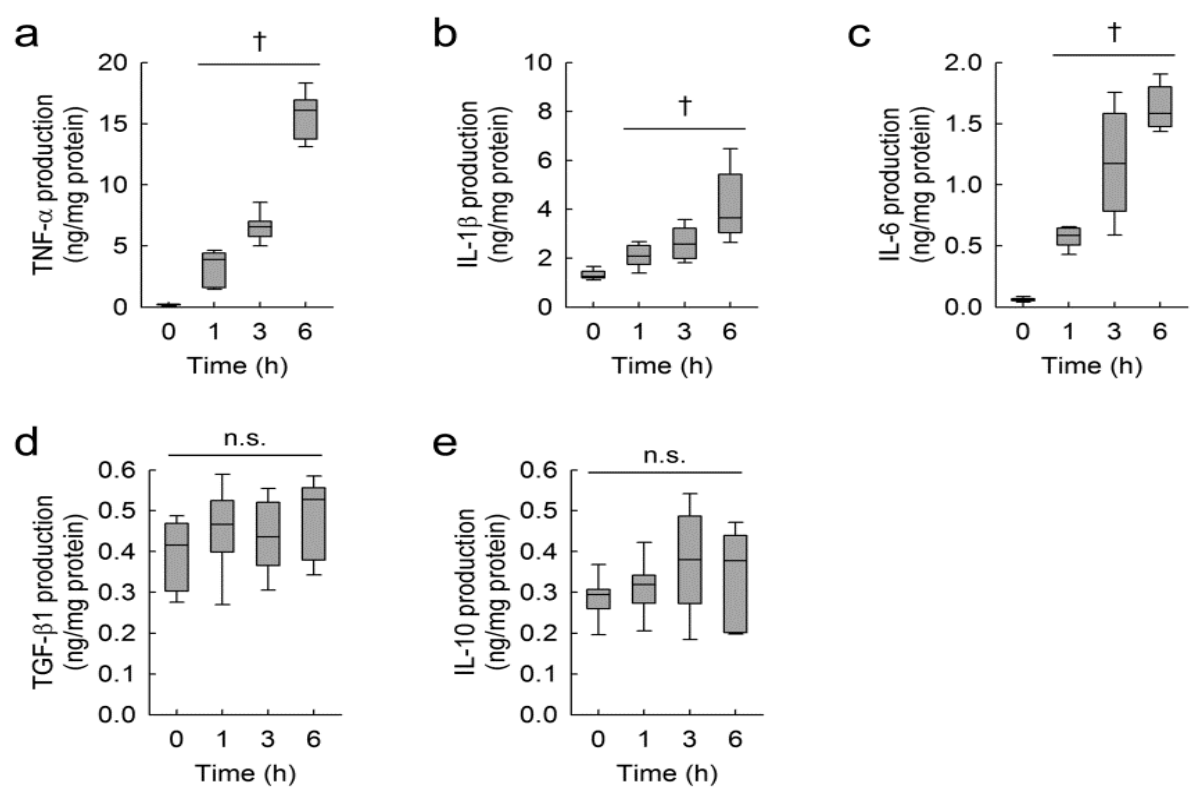

Figure 2. PM2.5 time-dependently upregulates proinflammationy cytokines in alveolar macrophages. $M H-S$ cells were treated with $30 \mu \mathrm{g} / \mathrm{ml}$ of PM2.5 for $0,1,3$, or $6 \mathrm{~h}(n=9$ cultures in each group). Intracellular levels of cytokine TNF- $\alpha, I L-1 \beta, I L-6, T G F-\beta 1$ and IL10 were measured using the multiplex immunoassay. In the box plots, whiskers represent the minimum and maximum; boxes represent the interquartile range between the first and third quartiles; and midlines represent the median. $\uparrow P<0.001$ versus $0 h ; n . s$., not significant

\section{PM2.5 stimulates M1 phenotypic polarization in alveolar macrophages}

Generally, macrophages are polarized into two distinct phenotypes: classically activated macrophages (M1) and alternatively activated macrophages (M2) (Sica and Mantovani, 2012). M1 macrophages upregulate proinflammatory cytokines including TNF- $\alpha$, IL-1 $\beta$, and IL-6, while M2 macrophages upregulate anti-inflammatory cytokines including TGF- $\beta 1$ and IL-10 (Arango Duque and Descoteaux, 2014). The results shown in Fig. 1 and 2 indicate that PM2.5 promotes alveolar macrophage polarization toward a M1-like proinflammatory phenotype. To investigate the phenotypic character of alveolar macrophages during PM2.5 exposure, the mRNA expression of the M1/M2 marker genes was evaluated at $24 \mathrm{~h}$ after PM2.5 administration in the MH-S cells. PM2.5 significantly increased the mRNA level of M1 marker CD80 in a dose-dependent manner, while it did not alter the mRNA level of M2 marker CD163 (Fig. 3, $a$ and b). Within $24 \mathrm{~h}$ after PM2.5 administration, the intracellular levels of CD80 mRNA expression were also increased, while the level of CD163 mRNA expression was not altered (Fig. 3, $c$ and $d$ ). Therefore, these data suggest that PM2.5 directly stimulates polarization toward a M1 phenotype in alveolar macrophages.

\section{NF-кB inhibition attenuates PM2.5-induced proinflammatory cytokine upregulation in alveolar macrophages}

The NF- $\kappa \mathrm{B}$ transcriptional factor plays an essential role in the transduction signals involved in the expression of a number of inflammatory genes (Lenardo and Baltimore, 1989) and is activated by PM2.5 in alveolar epithelial cells and peripheral macrophages 
(Dagher et al., 2007; He et al., 2017). As shown in Fig. 4, the p65 protein as a major subunit of NF- $\kappa \mathrm{B}$ was also dose-dependently activated by exposure to PM2.5 in alveolar macrophages, as measured by the p65 phosphorylation and DNA-binding activity in the MH-S cells at $6 \mathrm{~h}$ after PM2.5 administration.
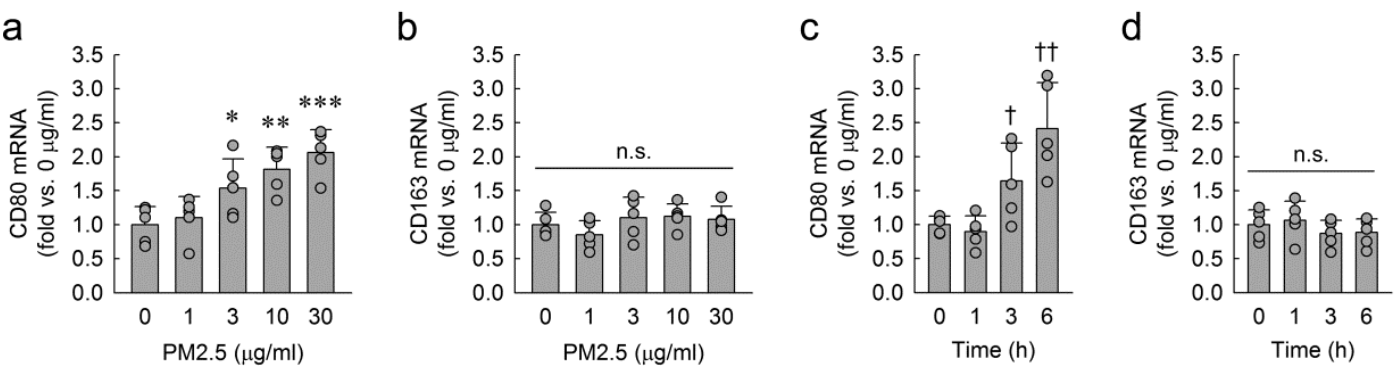

Figure 3. PM2.5 increases CD80 mRNA expression, but not CD163 mRNA in alveolar macrophages. ( $a$ and b) MH-S cells were treated with 0, 1, 3, 10, or $30 \mu \mathrm{g} / \mathrm{ml}$ of PM2.5 for $24 \mathrm{~h}$ ( $n=5$ cultures in each group). ( $c$ and d) MH-S cells were treated with $30 \mu \mathrm{g} / \mathrm{ml}$ of PM2.5 for 0 , 1,3 , or 6 h ( $n=5$ cultures in each group). Intracellular levels of CD80 and CD163 mRNA were measured using real-time quantitative $R T-P C R$. *P<0.05, **P<0.01, and $* * P<0.001$ versus 0 $\mu \mathrm{g} / \mathrm{ml}$. Data are shown as mean + s.d. $\uparrow P<0.05$ and $\uparrow \uparrow P<0.01$ versus 0 h; n.s., not significant

a

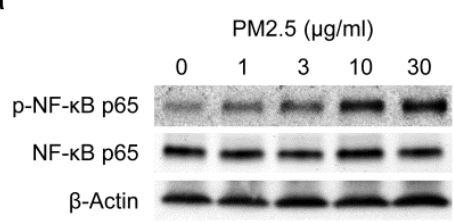

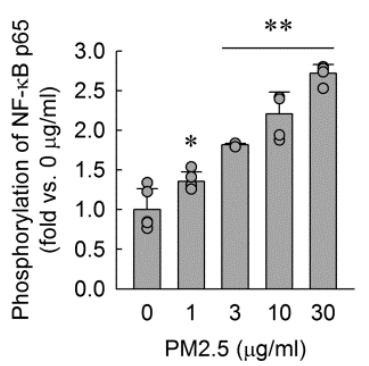

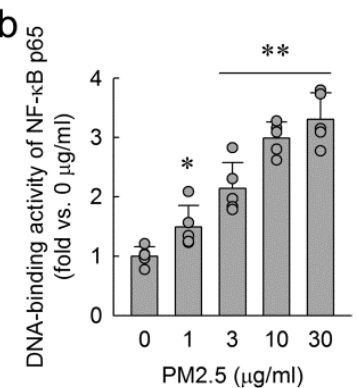

Figure 4. PM2.5 activates $N F-\kappa B$ transcription factor in alveolar macrophages. $M H-S$ cells were treated with $0,1,3,10$, or $30 \mu \mathrm{g} / \mathrm{ml}$ of PM2.5 for $24 \mathrm{~h}$ ( $\mathrm{n}=5$ cultures in each group). (a)

$N F-\kappa B$ p65 phosphorylation ( $p-N F-\kappa B p 65$ ) and its total expression ( $N F-\kappa B p 65$ ) were examined using western blot analysis. Anti- $\beta$-actin antibody was used as a loading control. The intensities of these protein bands were quantified using the AzureSpot software (Azure Biosystems). (b) DNA-binding activities of $N F-\kappa B$ p 65 were measured in the nuclear extracts of cells using the TransAM NF- $\kappa B$ p 65 transcription factor assay kit (Active Motif). Data are shown as mean + s.d. ${ }^{*} P<0.05$ and $* * P<0.001$ versus $0 \mu \mathrm{g} / \mathrm{ml}$

To determine whether PM2.5 exposure upregulates proinflammatory cytokines through $\mathrm{NF}-\kappa \mathrm{B}$ activation in alveolar macrophages, we treated with the two types of specific NF- $\kappa$ B inhibitors including Ro 106-9920 and PDTC in the MH-S cells. Treatments with the NF- $\kappa$ B inhibitors markedly reduced TNF- $\alpha$, IL- $1 \beta$, and IL-6 cytokines upregulated by PM2.5 exposure in a dose-dependent manner (Fig. 5, a to c). In particular, compared to IL- $1 \beta$ production, the TNF- $\alpha$ and IL- 6 productions were more susceptible to a low concentration of these inhibitors $(1 \mu \mathrm{M})($ Fig. 5, a to $c)$. These data suggest that PM2.5 upregulates proinflammatory cytokines through NF- $\kappa \mathrm{B}$ activation in alveolar macrophages. 
a

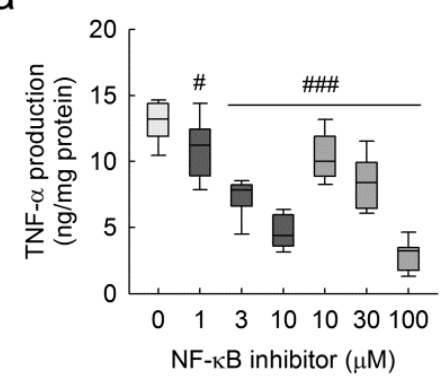

b

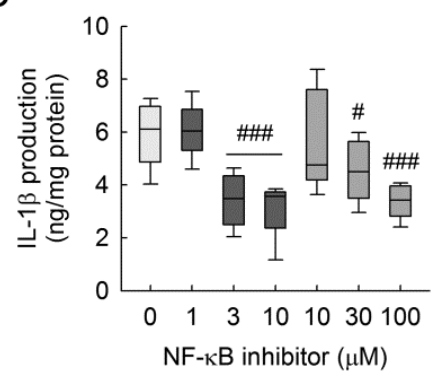

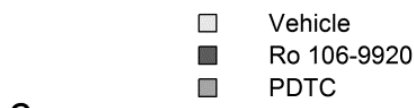

C

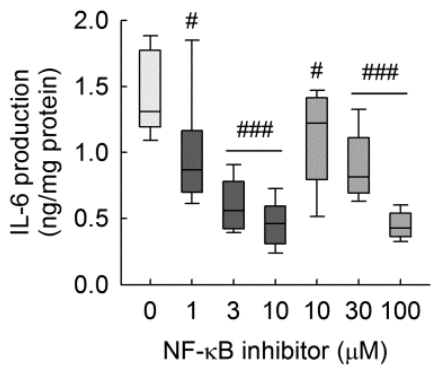

Figure 5. $N F-\kappa B$ inhibition attenuates proinflammatory cytokine upregulation induced by PM2.5 in alveolar macrophages. MH-S cells were treated with $30 \mu \mathrm{g} / \mathrm{ml}$ of PM2.5 for $24 \mathrm{~h}$.

Some cells were treated with either Ro 106-9920 (1 to $10 \mu \mathrm{M})$, PDTC (10 to $100 \mu \mathrm{M})$, or vehicle (0.1\% DMSO) immediately after PM2.5 administration ( $n=9$ cultures in each group).

Intracellular levels of cytokine TNF- $\alpha, I L-1 \beta$, and IL-6 were measured using multiplex

immunoassay. In the box plots, whiskers represent the minimum and maximum; boxes represent the interquartile range between the first and third quartiles; and midlines represent the median. $\# P<0.05$ and $\# \# P<0.001$ versus vehicle $(0 \mu M N F-\kappa B$ inhibitor $)$

\section{NF-אB inhibition suppresses PM2.5-induced M1 polarization in alveolar macrophages}

In order to examine whether the NF- $\kappa \mathrm{B}$ signaling pathway is involved in the PM2.5induced M1 polarization in alveolar macrophages, we assessed the mRNA expression of M1/M2 marker genes at $24 \mathrm{~h}$ after PM2.5 administration in MH-S cells. Consistent with the patterns of proinflammatory cytokine production, the mRNA level of the M1 marker CD80 in the PM2.5-treated cells was significantly attenuated by treatments with the NF$\kappa \mathrm{B}$ inhibitors in a dose-dependent manner (Fig. $6 a$ ). However, the mRNA level of the M2 marker CD163 was not altered by the NF- $\kappa$ B inhibitions (Fig. 6b). Therefore, these data suggest that the NF- $\kappa \mathrm{B}$ signaling pathway mediates the PM2.5-induced polarization of alveolar macrophages into M1 macrophages.
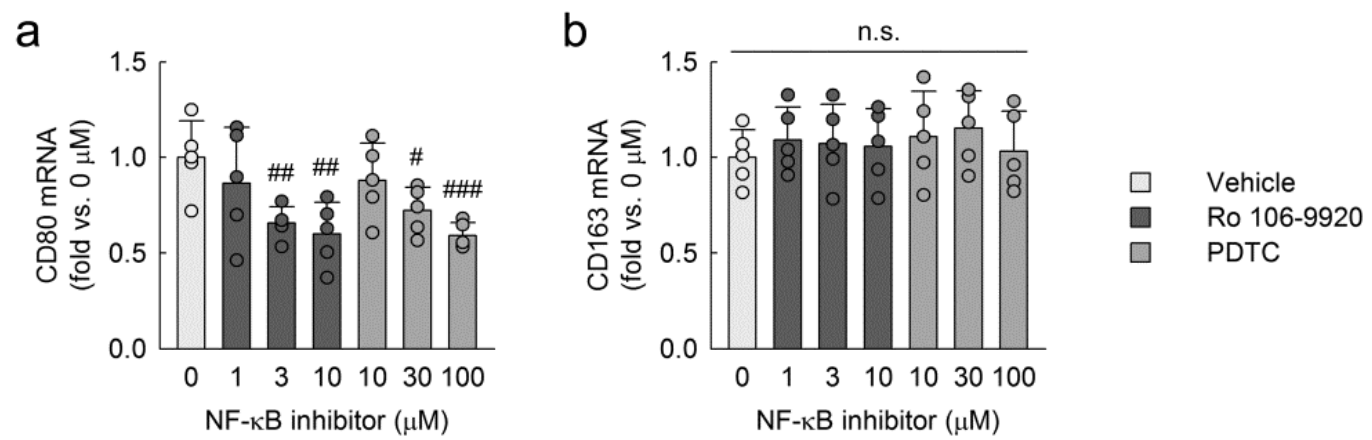

Figure 6. $N F-\kappa B$ inhibition suppresses CD80 mRNA expression induced by PM2.5 in alveolar macrophages. $M H-S$ cells were treated with $30 \mu \mathrm{g} / \mathrm{ml}$ of PM2.5 for $24 \mathrm{~h}$. Some cells were treated with either Ro 106-9920 (1 to $10 \mu \mathrm{M})$, PDTC (10 to $100 \mu \mathrm{M})$, or vehicle (0.1\% DMSO) immediately after PM2.5 administration ( $n=5$ cultures in each group). Intracellular levels of $C D 80$ and CD163 mRNA were measured using real-time quantitative RT-PCR ( $n=5$ cultures in each group). Data are shown as mean + s.d. \#P<0.05, \#\#P<0.01, and \#\#\#P<0.001 versus vehicle (0 $\mu M N F-\kappa B$ inhibitor); n.s., not significant 


\section{Discussion}

Atmospheric PM pollution is a serious global issue. Long-term exposure to PM2.5 has been epidemiologically associated with respiratory mortality and disease (Kim et al., 2015b). Furthermore, PM2.5 concentration is implicated in the increasing number of incidences of upper respiratory tract infection, asthma, acute pulmonary disease (Cohen et al., 2005). Recently, many investigators have attempted to reveal associations of exposure to PM2.5 with respiratory inflammation through epidemiology and in vivo experiments. However, to protect against PM2.5-induced pulmonary inflammation, understanding of the underlying molecular mechanisms during the initiation and progression of inflammation is required. In this study, we found that in $\mathrm{MH}-\mathrm{S}$ mouse alveolar macrophages, PM2.5 exposure upregulates proinflammatory cytokines and stimulates M1 macrophage polarization through the $\mathrm{NF}-\kappa \mathrm{B}$ signaling pathway. Our present data suggest that the NF- $\mathrm{BB}$ signaling plays a central role in proinflammatory macrophages during the development of pulmonary inflammation.

The alveolar macrophage has important microbicidal, phagocytic, and secretory functions and plays a distinctive role in lung immunity by initiating inflammatory and immune responses (Oberdörster et al., 1992). Furthermore, in order to sustain a wellorganized host defense response, alveolar macrophages communicate with other cellular components of the innate immune system. Among the components, cytokines such as TNF- $\alpha$, IL-1 $\beta$, and IL-6 play a critical role in the pulmonary host defense. While inflammatory cytokines are beneficial for the host when produced in appropriate amounts, they are toxic when produced in a deregulated fashion. In this study, the TNFa, IL-1 3 , and IL-6 cytokines produced by PM2.5 exposure in alveolar macrphages appeared to be similar to previously reported in vitro responses in either peritoneal macrophages or macrophage-like cell lines, which were not derived from the lung (Migliaccio et al., 2013; Pozzi et al., 2003; Soukup and Becker, 2001a). In addition, PM2.5 and its microenvironment directly affect the phenotype and function of primary mouse peritoneal macrophages; PM2.5 significantly enhances inflammatory M1 polarization and inhibits anti-inflammatory M2 polarization (Zhao et al., 2016). Interestingly, our data reveal that PM2.5 exposure in alveolar macrophages consistently stimulates M1 phenotypic polarization, as indicated by the high CD80 mRNA expression, while M2 phenotypic polarization is not affected by PM2.5 exposure as indicated by the non-altered CD163 mRNA expression. This possibility is supported by previous reports demonstrating that PM2.5 induces proinflammatory gene expression, while it does not contribute to anti-inflammation in other cells, including airway epithelial cells (Baulig et al., 2009), bronchial epithelial cells (Cachon et al., 2014), and peritoneal macrophages (Pozzi et al., 2003).

$\mathrm{NF}-\kappa \mathrm{B}$ transcription factors have been shown to transactivate a number of cytokines, chemokines, cell adhesion molecules, and receptors implicated in lung diseases (Yamamoto and Gaynor, 2001). PM2.5 and its components activate the NF- $\kappa B$ signaling pathway in lung and airway epithelial cells (Dagher et al., 2007; Marano et al., 2002). Consistent with this finding, our data demonstrates that PM2.5 exposure in alveolar macrophages induces NF- $\mathrm{BB}$ activation, leading to the upregulation of TNF- $\alpha$, IL-1 $\beta$, and IL-6 cytokines. Among the anti-inflammatory cytokines shown in our present data, IL-10 can be transactivated by NF- $\kappa B$ (Cao et al., 2006). The previous study showed that the homodimers of $N F-\kappa B$ transcription factor bind to the $\mathrm{Il10}$ promoter in primary peritoneal macrophages, and loss of NF- $\kappa \mathrm{B}$ subunit alters the IL-10 expression induced by lipopolysaccharide exposure (Cao et al., 2006). However, our 
present data showed that PM2.5-treated alveolar macrophages show NF- $\kappa \mathrm{B}$ signaling activation, but do not alter the production of IL-10 protein. In addition to NF- $\kappa B$, the expression of IL-10 can be regulated by other transcription factors including specific protein 1 (SP1), SP3, CCAAT/enhancer binding protein- $\beta$ (C/EBP $\beta)$, interferonregulatory factor 1 (IRF1), and signal transducer and activator of transcription 3 (STAT3) in macrophages (Saraiva and O'Garra, 2010), suggesting that the intracellular level of IL-10 production is independent of the NF- $\kappa B$ signaling. Therefore, the NF- $\kappa B$ activation induced by PM2.5 in alveolar macrophages specifically mediates the upregulation of proinflammatory cytokines as well as the polarization toward M1 phenotype. Previous reports have also supported that the NF- $\kappa \mathrm{B}$ activation is essential for determining M1 polarization in macrophages (Barberi et al., 2015; Jang et al., 2013). Furthermore, the expression of the M1 marker CD80 is regulated and responsive to the NF- $\kappa \mathrm{B}$ activation (Zhao et al., 1996).

\section{Conclusion}

The present results demonstrate that PM2.5 exposure induces the upregulation of proinflammatory cytokines TNF- $\alpha$, IL- $1 \beta$, and IL- 6 through the NF- $\kappa$ B activation in alveolar macrophages and the polarization of alveolar macrophages to M1 phenotype. Furthermore, the results show that this mechanism might induce the inflammation cascade and pulmonary diseases. It is expected that inhibiting the NF- $\kappa \mathrm{B}$ action will represent an effective therapeutic strategy to prevent or limit macrophage inflammation in pulmonary disease patients. In future studies using animal models of chronic obstructive pulmonary disease and acute lung injury, it needs to seek to determine whether PM2.5 induces pulmonary inflammation through the polarization of alveolar macrophages, and if so, whether PM2.5-induced inflammatory responses in alveolar macrophages is implicated in the activation of NF- $\kappa \mathrm{B}$. Finally, it needs to assess whether the genetic inhibition of $\mathrm{NF}-\mathrm{\kappa B}$ suppresses the development of pulmonary inflammation and diseases after exposure to PM2.5 in those animal models.

Acknowledgements. This work was supported by the research grant of the Jeju National University Hospital in 2015.

\section{REFERENCES}

[1] Abbey, D. E., Ostro, B. E., Petersen, F., Burchette, R. J. (1995): Chronic respiratory symptoms associated with estimated long-term ambient concentrations of fine particulates less than 2.5 microns in aerodynamic diameter (PM2.5) and other air pollutants. - J Expo Anal Environ Epidemiol 5: 137-159.

[2] Anderson, J. O., Thundiyil, J. G., Stolbach, A. (2012): Clearing the air: a review of the effects of particulate matter air pollution on human health. - J Med Toxicol 8: 166-175.

[3] Arango Duque, G., Descoteaux, A. (2014): Macrophage cytokines: involvement in immunity and infectious diseases. - Front Immunol 5: 491.

[4] Barberi, T., Martin, A., Harris-Bookman, S., Lim, M., Friedman, A. D. (2015): Deletion of NF-kB p50 alters murine glioblastoma tumor-associated macrophage polarization, reduces tumor growth and prolongs survival. - Journal for Immunotherapy of Cancer 3 (Suppl 2): 395. 
[5] Baulig, A., Singh, S., Marchand, A., Schins, R., Barouki, R., Garlatti, M., Marano, F. (2009): Role of Paris PM(2.5) components in the pro-inflammatory response induced in airway epithelial cells. - Toxicology 261: 126-135.

[6] Cachon, B. F., Firmin, S., Verdin, A., Ayi-Fanou, L., Billet, S., Cazier, F., Martin, P. J. (2014): Proinflammatory effects and oxidative stress within human bronchial epithelial cells exposed to atmospheric particulate matter $(\operatorname{PM}(2.5)$ and $\mathrm{PM}(>2.5))$ collected from Cotonou, Benin. - Environ Pollut 185: 340-351.

[7] Cao, S., Zhang, X., Edwards, J. P., Mosser, D. M. (2006): NF-kappaB1 (p50) homodimers differentially regulate pro- and anti-inflammatory cytokines in macrophages. - J Biol Chem 281: 26041-26050.

[8] Cohen, A. J., Ross Anderson, H., Ostro, B., Pandey, K. D., Krzyzanowski, M., Kunzli, N., Gutschmidt, K. (2005): The global burden of disease due to outdoor air pollution. - J Toxicol Environ Health A 68: 1301-1307.

[9] Corsini, E., Budello, S., Marabini, L., Galbiati, V., Piazzalunga, A., Barbieri, P., Cozzutto, S. (2013): Comparison of wood smoke PM2.5 obtained from the combustion of FIR and beech pellets on inflammation and DNA damage in A549 and THP-1 human cell lines. - Arch Toxicol 87: 2187-2199.

[10] Dagher, Z., Garcon, G., Billet, S., Verdin, A., Ledoux, F., Courcot, D., Aboukais, A. (2007): Role of nuclear factor-kappa B activation in the adverse effects induced by air pollution particulate matter (PM2.5) in human epithelial lung cells (L132) in culture. - J Appl Toxicol 27: 284-290.

[11] Deng, X., Zhang, F., Rui, W., Long, F., Wang, L., Feng, Z., Chen, D. (2013): PM2.5induced oxidative stress triggers autophagy in human lung epithelial A549 cells. Toxicology in vitro 27: 1762-1770.

[12] Gordon, S. (2007): The macrophage: past, present and future. - Eur J Immunol 37 (Suppl 1): S9-17.

[13] He, M., Ichinose, T., Yoshida, S., Ito, T., He, C., Yoshida, Y., Arashidani, K. (2017): PM2.5-induced lung inflammation in mice: Differences of inflammatory response in macrophages and type II alveolar cells. - J Appl Toxicol 37: 1203-1218.

[14] Hetland, R. B., Cassee, F. R., Lag, M., Refsnes, M., Dybing, E., Schwarze, P. E. (2005): Cytokine release from alveolar macrophages exposed to ambient particulate matter: heterogeneity in relation to size, city and season. - Part Fibre Toxicol 2: 4.

[15] Hocking, W. G., Golde, D. W. (1979): The pulmonary-alveolar macrophage. - New England Journal of Medicine 301: 639-645.

[16] Jalava, P. I., Salonen, R. O., Pennanen, A. S., Sillanpaa, M., Halinen, A. I., Happo, M. S., Hillamo, R. (2007): Heterogeneities in inflammatory and cytotoxic responses of RAW 264.7 macrophage cell line to urban air coarse, fine, and ultrafine particles from six European sampling campaigns. - Inhal Toxicol 19: 213-225.

[17] Jang, S. E., Hyam, S. R., Han, M. J., Kim, S. Y., Lee, B. G., Kim, D. H. (2013): Lactobacillus brevis G-101 ameliorates colitis in mice by inhibiting NF-kappaB, MAPK and AKT pathways and by polarizing M1 macrophages to M2-like macrophages. - J Appl Microbiol 115: 888-896.

[18] Kampa, M., Castanas, E. (2008): Human health effects of air pollution. - Environ Pollut 151: 362-367.

[19] Kim, J. (2016): Poly(ADP-ribose) polymerase activation induces high mobility group box 1 release from proximal tubular cells during cisplatin nephrotoxicity. - Physiol Res 65: 333-340.

[20] Kim, J. (2017a): Spermidine rescues proximal tubular cells from oxidative stress and necrosis after ischemic acute kidney injury. - Arch Pharm Res 40: 1197-1208.

[21] Kim, J. (2017b): Spermidine is protective against kidney ischemia and reperfusion injury through inhibiting DNA nitration and PARP1 activation. - Anat Cell Biol 50: 200-206.

[22] Kim, J., Long, K. E., Tang, K., Padanilam, B. J. (2012): Poly(ADP-ribose) polymerase 1 activation is required for cisplatin nephrotoxicity. - Kidney Int 82: 193-203. 
[23] Kim, J., Imig, J. D., Yang, J., Hammock, B. D., Padanilam, B. J. (2014): Inhibition of soluble epoxide hydrolase prevents renal interstitial fibrosis and inflammation. - Am J Physiol Renal Physiol 307: F971-980.

[24] Kim, J., Yoon, S. P., Toews, M. L., Imig, J. D., Hwang, S. H., Hammock, B. D., Padanilam, B. J. (2015a): Pharmacological inhibition of soluble epoxide hydrolase prevents renal interstitial fibrogenesis in obstructive nephropathy. - Am J Physiol Renal Physiol 308: F131-139.

[25] Kim, K. H., Kabir, E., Kabir, S. (2015b): A review on the human health impact of airborne particulate matter. - Environ Int 74: 136-143.

[26] Ko, F. W., Tam, W., Wong, T. W., Chan, D. P., Tung, A. H., Lai, C. K., Hui, D. S. (2007): Temporal relationship between air pollutants and hospital admissions for chronic obstructive pulmonary disease in Hong Kong. - Thorax 62: 780-785.

[27] Lee, J. S., Lim, J. Y., Kim, J. (2015): Mechanical stretch induces angiotensinogen expression through PARP1 activation in kidney proximal tubular cells. - In Vitro Cell Dev Biol Anim 51: 72-78.

[28] Lenardo, M. J., Baltimore, D. (1989): NF-kappa B: a pleiotropic mediator of inducible and tissue-specific gene control. - Cell 58: 227-229.

[29] Marano, F., Boland, S., Bonvallot, V., Baulig, A., Baeza-Squiban, A. (2002): Human airway epithelial cells in culture for studying the molecular mechanisms of the inflammatory response triggered by diesel exhaust particles. - Cell Biol Toxicol 18: 315320.

[30] Martinez, F. O., Sica, A., Mantovani, A., Locati, M. (2008): Macrophage activation and polarization. - Front Biosci 13: 453-461.

[31] Migliaccio, C. T., Kobos, E., King, Q. O., Porter, V., Jessop, F., Ward, T. (2013): Adverse effects of wood smoke PM2. 5 exposure on macrophage functions. - Inhalation toxicology 25: 67-76.

[32] Oberdörster, G., Ferin, J., Gelein, R., Soderholm, S. C., Finkelstein, J. (1992): Role of the alveolar macrophage in lung injury: studies with ultrafine particles. - Environ Health Perspect 97: 193.

[33] Park, S., Yoon, S. P., Kim, J. (2015): Cisplatin induces primary necrosis through poly(ADP-ribose) polymerase 1 activation in kidney proximal tubular cells. - Anat Cell Biol 48: 66-74.

[34] Pozzi, R., De Berardis, B., Paoletti, L., Guastadisegni, C. (2003): Inflammatory mediators induced by coarse (PM2.5-10) and fine (PM2. 5) urban air particles in RAW 264.7 cells. - Toxicology 183: 243-254.

[35] Riva, D., Magalhaes, C., Lopes, A. A., Lancas, T., Mauad, T., Malm, O., Valenca, S. (2011): Low dose of fine particulate matter (PM2. 5) can induce acute oxidative stress, inflammation and pulmonary impairment in healthy mice. - Inhalation Toxicology 23: 257-267.

[36] Saraiva, M., O'Garra, A. (2010): The regulation of IL-10 production by immune cells. Nat Rev Immunol 10: 170-181.

[37] Sica, A., Mantovani, A. (2012): Macrophage plasticity and polarization: in vivo veritas. J Clin Invest 122: 787-795.

[38] Song, H., Yoon, S. P., Kim, J. (2016): Poly(ADP-ribose) polymerase regulates glycolytic activity in kidney proximal tubule epithelial cells. - Anat Cell Biol 49: 79-87.

[39] Soukup, J. M., Becker, S. (2001a): Human alveolar macrophage responses to air pollution particulates are associated with insoluble components of coarse material, including particulate endotoxin. - Toxicol Appl Pharmacol 171: 20-26.

[40] Soukup, J. M., Becker, S. (2001b): Human alveolar macrophage responses to air pollution particulates are associated with insoluble components of coarse material, including particulate endotoxin. - Toxicol Appl Pharmacol 171: 20-26.

[41] Tecer, L. H., Alagha, O., Karaca, F., Tuncel, G., Eldes, N. (2008): Particulate matter $(\operatorname{PM}(2.5), \operatorname{PM}(10-2.5)$, and $\operatorname{PM}(10))$ and children's hospital admissions for asthma and 
respiratory diseases: a bidirectional case-crossover study. - J Toxicol Environ Health A 71: 512-520.

[42] Vinikoor-Imler, L. C., Davis, J. A., Luben, T. J. (2011): An ecologic analysis of countylevel PM2.5 concentrations and lung cancer incidence and mortality. - Int J Environ Res Public Health 8: 1865-1871.

[43] Wang, C., Yu, X., Cao, Q., Wang, Y., Zheng, G., Tan, T. K., Zhao, H. (2013): Characterization of murine macrophages from bone marrow, spleen and peritoneum. BMC Immunol 14: 6.

[44] Yamamoto, Y., Gaynor, R. B. (2001): Role of the NF-kappaB pathway in the pathogenesis of human disease states. - Curr Mol Med 1: 287-296.

[45] Yoon, S. P., Kim, J. (2015): Poly(ADP-ribose) polymerase 1 activation links ischemic acute kidney injury to interstitial fibrosis. - J Physiol Sci 65: 105-111.

[46] Yoon, S. P., Kim, J. (2016): Poly(ADP-ribose) polymerase 1 contributes to oxidative stress through downregulation of sirtuin 3 during cisplatin nephrotoxicity. - Anat Cell Biol 49: 165-176.

[47] Yoon, S. P., Kim, J. (2018a): Exogenous CGRP upregulates profibrogenic growth factors through PKC/JNK signaling pathway in kidney proximal tubular cells. - Cell Biol Toxicol 34: 251-262.

[48] Yoon, S. P., Kim, J. (2018b): Exogenous spermidine ameliorates tubular necrosis during cisplatin nephrotoxicity. - Anat Cell Biol 51: 189-199.

[49] Zhang, Y., Wang, S., Zhu, J., Li, C., Zhang, T., Liu, H., Xu, Q. (2018): Effect of Atmospheric PM2.5 on Expression Levels of NF-kappaB Genes and Inflammatory Cytokines Regulated by NF-kappaB in Human Macrophage. - Inflammation 41: 784-794.

[50] Zhao, J., Freeman, G. J., Gray, G. S., Nadler, L. M., Glimcher, L. H. (1996): A cell typespecific enhancer in the human B7.1 gene regulated by NF-kappaB. - J Exp Med 183: 777-789.

[51] Zhao, Q., Chen, H., Yang, T., Rui, W., Liu, F., Zhang, F., Zhao, Y. (2016): Direct effects of airborne PM2.5 exposure on macrophage polarizations. - Biochim Biophys Acta 1860: 2835-2843. 